\title{
MELHORIA DO DESEMPENHO COGNITIVO DOS ALUNOS DO ENSINO FUNDAMENTAL
}

\author{
JO SÉ FRAN CISC O SO ARES \\ Grupo de Avaliação e Medidas Educacionais, Faculdade \\ de Educação da Universidade Federal de Minas Gerais \\ francisco-soares@ufmg.br
}

\begin{abstract}
RESUMO
Este artigo introduz um modelo conceitual que relaciona fatores intra e extra-escolares a uma medida de desempenho cognitivo dos alunos. Com a ajuda desse esquema revisam-se as evidências presentes na literatura educacional sobre as possibilidades de melhoria dos resultados cognitivos dos alunos do ensino fundamental. Muitos dos resultados das pesquisas relatadas na literatura internacional não foram validados por estudos empíricos no Brasil atéo momento. Os melhores dados para estudo do assunto disponíveis no país são os do Sistema Nacional de Avaliação da Educação Básica - Saeb, que têm muitas limitações. No entanto, já é possivel garantir que, considerando o nivel atual do desempenho dos alunos, há ações que podem ser realizadas no nivel da escola com grande potencial de melhoria das proficiências dos alunos. Assim, neste momento, é preciso enfatizar as politicas escolares, tendo em vista que elas só serão viáveis com a implantação da autonomia das escolas, preceito já estabelecido em lei, mas ainda não completamente implementado.

DESENVOLVIMENTO COGNITIVO - RENDIMENTO ESCOLAR - ENSINO FUNDAMENTAL - AVALIAÇÃO DA EDUCAÇÃO
\end{abstract}

\section{ABSTRACT}

IMPROVING COGNITIVE PERFORMANCE OF STUDENTS ENROLLED IN ELEMENTARY SCHOOL. This paper introduces a conceptual model which relates intra and extra school factors to elementary school students' achievement. Using this model as reference, the main evidences from the literature on how to improve student's achievement were reviewed. However, it should be noted that several of the results published in the international literature haven't been replicated with data collected in Brazil. The best Brazilian data to study these questions are those from Brazilian System for Evaluation of Basic Education - Saeb. Considering the low level attained today by the Brazilian students, there are several actions, which can be taken at the school level that, if applied, will impact positively on the student's achievement. At this point in time, it is strategic to emphasize school policies, considering,

O autor agradece a Luana Marotta e Renato Júdice de Andrade por várias colaborações na manipulação dos dados do Saeb usados neste artigo. 
however, that they only will be viable with the implementation of school autonomy, idea already present in law, but not completely put into practice.

COGNITIVE DEVELOPMENT - STUDENT ACHIEVEMENT - ELEMENTARY SCHOOL CURSE EVALUATION

objetivo deste artigo é apresentar criticamente as evidências provenientes da literatura educacional e das análises dos dados resultantes dos grandes projetos de avaliação da educação básica no Brasil para a formulação e implementação de políticas públicas que possibilitem a melhoria dos resultados educacionais brasileiros. Para isso, é preciso antes de tudo delimitar mais claramente o problema.

A educação, na sua acepção mais ampla, tem objetivos que ultrapassam o raio de ação da escola. A própria Constituição brasileira' estabelece que a educação é dever do Estado e da família, ou seja, que a educação integral do ser humano exige a contribuição de outras estruturas sociais além da escola. No entanto, a escola e, conseqüentemente, o sistema escolar têm um papel diferenciado em relação à educação. De forma mais específica, essas estruturas devem possibilitar aos alunos oportunidades para a aquisição de competências cognitivas consideradas necessárias pela sociedade, prepará-los para o mundo do trabalho e para a vida em sociedade, e ainda desenvolver seus talentos individuais. Assim, o objetivo da educação escolar, aquela parte da educação que ocorre no âmbito do estabelecimento escolar, pode ser sintetizado na expressão: Instruir, mas também educar; ou educar através da instrução.

No amplo espectro da educação escolar, vamos nos concentrar na educação básica e, dentro dela, no ensino fundamental. Os outros níveis da educação básica, a educação infantil e o ensino médio, exigem reflexões específicas, que não podem ser feitas apenas com base nos dados gerados pelos atuais projetos de avaliação educacional. A análise da educação infantil deve levar em conta a dificuldade e a desigualdade de acesso a ela, e a do ensino médio requer a discussão das suas funções ${ }^{2}$. No caso da educação fundamental, já uni-

I. Art. 205. A educação, direito de todos e dever do Estado e da família, será promovida e incentivada com a colaboração da sociedade, visando o pleno desenvolvimento da pessoa, seu preparo para o exercício da cidadania e sua qualificação para o trabalho.

2. Para uma visão crítica das soluções adotadas para o ensino médio pode-se consultar Castro (2005). 
versalizada e com um papel consolidado no contexto da formação escolar dos alunos, a análise deve-se concentrar na definição de sua qualidade e nas formas de atingi-la.

\section{RESULTAD O S ESC O LARES}

Os resultados mais elementares do sistema escolar são o acesso e o fluxo dos alunos. Essas duas dimensões são verificadas através do Censo Escolar, do Censo Demográfico e da Pesquisa Nacional por Amostra de Domicílios $\mathrm{PNAD}^{3}$. Nos questionários destes dois últimos levantamentos, o número de questões relativas à educação escolar é pequeno. No entanto, produzem dados que permitem o cálculo de indicadores muito úteis para a descrição do sistema escolar do país, em particular, as taxas de analfabetismo, as taxas de escolarização bruta e líquida e o número de anos de estudo. Nos anos de realização do Censo Demográfico, essas taxas podem ser calculadas para todos os municípios do país, constituindo-se nos únicos dados municipais com abrangência nacional disponíveis para descrição dos resultados do sistema escolar ${ }^{4}$.

As informações obtidas mostram que o ensino fundamental no Brasil está praticamente universalizado para as crianças e adolescentes de 7 a 14 anos, uma vitória alcançada com décadas de atraso, mesmo em relação a países de menor desenvolvimento econômico da América Latina. É preciso ressaltar, porém, que o direito constitucional ao ensino fundamental não se restringe aos cidadãos daquela idade, e que hoje o sistema educacional brasileiro não tem capacidade sequer para absorver uma pequena parte das crianças que ainda não exercem esse direito, caso decidam buscá-lo proximamente.

Outros indicadores do funcionamento do sistema escolar, como o tempo médio de conclusão, são produzidos pelos modelos de fluxo escolar desenvolvidos por Klein (2003) e Rios-Neto (2004) com base nos dados da PNAD

3. Pesquisa realizada pelo Instituto Brasileiro de Geografia e Estatística - IBGE - em uma amostra aleatória de domicílios de todas as unidades da federação, com exceção da zona rural da Região Norte.

4. $\bigcirc$ Estado de Minas Gerais, através da Fundação João Pinheiro, concluiu recentemente o Atlas da Educação de Minas Gerais, que agrega em um CD de fácil utilização todas as informações sobre as várias dimensões do acesso à educação escolar, viabilizadas pelo Censo Escolar, PNAD, Censo Demográfico e projeções populacionais necessárias para a estimativa das taxas de escolarização nos anos intercensitários. 
e também do Censo Escolar. Os resultados destes trabalhos indicam que persistem graves e sérios problemas no ensino fundamental. As taxas de repetência e de abandono e a distorção idade-série continuam em níveis elevados, impossibilitando, por exemplo, a desejada universalização do ensino médio, além de significar um grande desperdício de recursos.

\section{Medida de resultados cognitivos}

Apesar da importância dos indicadores de acesso e fluxo, neste artigo vamos analisar a educação fundamental através do desempenho cognitivo dos alunos. Sem aprendizado e a conseqüente percepção de sua utilidade, dificilmente o aluno continua a freqüentar a escola. Esses são pontos fundamentais na definição de qualidade do ensino fundamental, e estão entre as metas educacionais acertadas no acordo internacional denominado Education for all (Unesco, 2005), cujo cumprimento é verificado anualmente pela instituição. Assim a melhoria do ensino básico significa neste texto a elevação dos níveis de aprendizado dos alunos, medido em escalas especificamente desenvolvidas para esse fim.

De forma muito lenta vai se firmando no Brasil a idéia já amplamente consolidada em outros países de que apenas através da medida dos resultados cognitivos é possível conhecer e analisar os níveis da aprendizagem de grande número de alunos e a qualidade do serviço prestado pelas escolas de um sistema. É óbvio que uma única medida de desempenho não capta particularidades que devem ser registradas no acompanhamento rotineiro de cada aluno por seus professores. Nessa dimensão, todo aluno tem o direito de ser avaliado, pois só assim é possível conhecer suas deficiências e fornecer-lhe um auxílio específico.

Para medir o resultado cognitivo de alunos do ensino básico, o Instituto Nacional de Pesquisas Educacionais - Inep - criou em 1995, dentro do esforço de consolidação do Sistema Nacional de Avaliação da Educação Básica, escalas de competências matemática e leitora. Os detalhes desse processo estão registrados no trabalho de Klein e Fontanive (1995), pioneiros na construção dessas escalas. O relatório do Saeb de 200 I, disponível no sítio do Inep, é particularmente útil para o entendimento dos aspectos pedagógicos e estatísticos associados a elas. 
TABELA I

PORCENTAGEM DE ALUNOS NOS NÍVEIS BÁSICO

E RECOMENDADO NO SAEB 2003

\begin{tabular}{ccccc}
\hline & \multicolumn{2}{c}{ Matemática } & \multicolumn{2}{c}{ Língua Portuguesa } \\
\hline Série & $<$ Básico & $>$ Recomendado & $<$ Básico & $>$ Recomendado \\
\hline 4 E.F. & 51,6 & 29,0 & 55,0 & 25,6 \\
8 E.F. & 57,1 & 14,7 & 45,6 & 20,1 \\
3a E.M. & 79,1 & 6,9 & 38,6 & 26,9 \\
\hline
\end{tabular}

Fonte: Saeb 2003.

A tabela 2, referente aos dados do Saeb 2003, mostra porcentagens de alunos abaixo do nível básico e acima do nível recomendado, na nomenclatura do Sistema Mineiro de Avaliação da Educação Básica - Simave ${ }^{5}$. Pode-se observar que, em termos de desempenho dos alunos, o sistema brasileiro de educação fundamental tem muito a melhorar.

\section{MODELO CONCEITUAL}

Como já dissemos, o principal objetivo deste artigo é informar sobre as possibilidades de melhoria do desempenho cognitivo dos alunos do ensino fundamental brasileiro. Para estudar esta questão, seja teoricamente seja empiricamente, é preciso explicitar um modelo conceitual que apresente as várias inter-relações entre os fatores explicativos do aprendizado e destes com o resultado final, aqui tomado como o desempenho cognitivo.

Os modelos existentes pertencem a duas tradições acadêmicas distintas; uma associada aos economistas e a outra a educadores e sociólogos da educação. Os primeiros se apóiam quase que exclusivamente nos dados do Censo Demográfico e da PNAD e priorizam os fatores extra-escolares, minimizando as oportunidades de melhoria por transformações nas políticas e práticas internas da escola. Essa visão é muito bem ilustrada no trabalho de Barros et al. (200 I), uma contribuição importante que analisa de forma exaustiva dados de três censos, e no ensaio de loschpe (2004). No âmbito internacional, essa

5. Muitos autores têm optado por diferentes pontos de corte e termos para nomear os níveis. Adotamos os do Simave pelo pequeno número e uso de descrições mais neutras. 
linha de raciocínio é muito desenvolvida, como mostram trabalhos recentes de Nechyba, McEwan, Older-Aguilar (2004), autores que fizeram uma exaustiva revisão da literatura sobre o assunto para o Ministério da Educação da Nova Zelândia.

Essa opção metodológica minimiza o papel da escola e prioriza as possibilidades de mudança via políticas extra-escolares e é muito prevalente entre economistas, profissionais que, mais do que quaisquer outros grupos, influenciam a escolha das políticas públicas dos governos em diferentes níveis. Sólidas evidências empíricas sustentam essa posição.

A literatura educacional mostra, além da dúvida razoável, que, em uma sociedade específica, os maiores determinantes do desempenho escolar estão fora do âmbito da escola. Ao revelarem um irrefutável determinismo sociológi$\mathrm{co}$, as pesquisas criaram também um forte pessimismo pedagógico, visto que levaram à conclusão que a escola pesaria pouco na explicação da variação do desempenho dos alunos. Essa idéia está sintetizada na frase provocante "as escolas não fazem diferença”, associada diretamente aos resultados do Relatório Coleman (Coleman et al., 1966). Em outra vertente, os estudos longitudinais realizados na França encontram-se na gênese do paradigma da reprodução, como se convencionou chamar o conjunto de teorias desenvolvidas por sociólogos franceses, sobretudo a partir da obra de Pierre Bourdieu. A reprodução à qual se referiu Bourdieu é a reprodução das desigualdades sociais no seio da instituição escolar e suas conseqüências em termos de mobilidade social.

Esses trabalhos mostram que cada sociedade define para si, através de suas opções históricas, um patamar possível para o aprendizado de seus estudantes. Entretanto, em torno dessa estrutura, característica da sociedade, há grande variação. Em sociedades desiguais, como a brasileira, o nível esperado de desempenho oscila de forma acentuada de acordo com o nível socioeconômico, ainda que haja grande variação em torno dessa tendência.

O sistema escolar por si só não é capaz mudar esta determinação social, mas algumas escolas conseguem em maior ou menor medida que seus alunos tenham um aprendizado melhor que o esperado para suas condições sociais. Os alunos dessas escolas têm um desempenho acima da linha que define a determinação social. Ou seja, o efeito da escola é relevante e decisivo, embora não possa mudar completamente a determinação social. Portanto, planejar o aumento do desempenho escolar de alunos do ensino básico utilizando ape- 
nas intervenções escolares implica aceitar, para a questão global, pequenos aumentos. Ainda assim, como mostram os dados empíricos, na situação atual do sistema de ensino básico no Brasil, onde prevalecem desempenhos muito baixos, existem oportunidades de melhorias substanciais de desempenho por meio de políticas escolares. É por isso que a pesquisa sobre o efeito escola é tão importante no nosso meio. E está claro também que mudanças em escolas específicas podem ser o passo inicial para transformações mais gerais. Finalmente, a ação sobre os fatores escolares pode ser feita a curto prazo enquanto a mudança das estruturas sociais só ocorre a longo prazo. Daí a relevância de considerar intervenções escolares.

A figura I apresenta o modelo elaborado por Soares (2005), fruto de uma consolidação de vários outros modelos existentes na literatura, principalmente os de Scheerens e Bosker (1997), Lee, Bryk, Smith (1993) e Gautthier (1997).

Ao se analisar esse modelo, é preciso considerar antes de tudo a complexidade do fenômeno que se pretende estudar. Os fatores mais próximos do

FIGURA I

MODELO CONCEITUAL

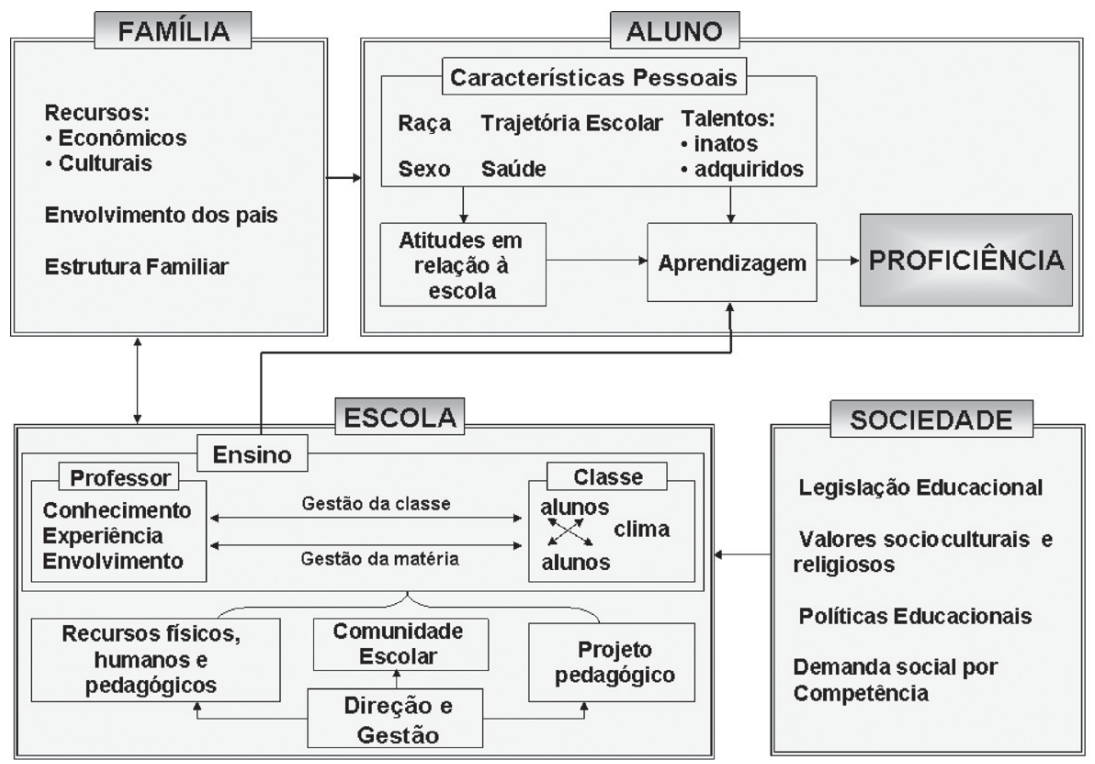


desempenho do aluno são suas características inatas ou já determinadas por sua história de vida. Além dessas, três outras estruturas concorrem para meIhores ou piores desempenhos de alunos: a escola, a família e a sociedade.

Assim, para o entendimento completo do desempenho do aluno é necessária uma abordagem multidisciplinar que agregue conhecimentos pelo menos da psicologia, da educação, da sociologia, da economia e inclusive da ciência política, em muitos momentos subsidiados pela coleta e análise de dados através de técnicas estatísticas apropriadas. As próximas seções apresentam uma elaboração sobre estes fatores e as oportunidades que indicam para a melhoria do desempenho dos alunos. Esta apresentação tem, entretanto, dois condicionantes que devem ser explicitados.

Primeiramente, adota-se a posição de Franco (2006) que salienta ser urgente no Brasil de hoje a "desinterdição" de todos os temas e de todas as abordagens de maneira que a pesquisa e o debate sobre questões educacionais possam subsidiar a formulação de políticas adequadas para a enorme diversidade de situações e problemas educacionais que afligem o Brasil. Ou seja, assume-se que a organização democrática de nossa sociedade dá a sustentação necessária para o estabelecimento de um diálogo produtivo entre diferentes escolas de pensamento educacional. Implicitamente, assume-se também que o Estado democrático brasileiro não deve apoiar apenas uma pedagogia, mas muitas, todas as que forem necessárias para se tratar da diversidade dos alunos do país.

Estamos longe desse ideal. $\bigcirc$ debate educacional brasileiro costuma admitir a existência de apenas duas posições antípodas que, ao invés de dialogarem, se insultam mutuamente. Meirieu (2005), apesar de se referir a uma outra realidade, expressa bem a dicotomia ao falar da posição "do mercado", que transforma a educação em bem de consumo e os pais e alunos em clientes que querem apenas obter resultados cognitivos. Para atendê-los, a escola adota uma pedagogia completamente instrumental. A função da pesquisa educacional se limitaria à busca da eficiência escolar imediata, e o ideal seria que se estabelecesse uma concorrência entre escolas e que a escola pública fosse privatizada. A posição oposta é descrita também caricaturalmente como uma posição de "irresponsabilidade social". Nesse caso, a escola é insensível às necessidades de seus alunos ou dos pais e insiste em que sua função não pode ser descrita objetivamente. A pedagogia apropriada é a da cumplicidade cultu- 
ral, do dom. Nenhum controle social é aceito, pois a escola tem uma função delegada pelo Estado que não pode ser retirada ou questionada. A sociedade deve fornecer à escola os meios que esta estabelece, de modo que o sistema educacional é, na prática, prisioneiro das corporações internas à escola.

Além da hipótese de que o diálogo é possível, argumenta-se que, para muitas das decisões sobre o sistema escolar brasileiro, não existem dados de pesquisa empírica que possam subsidiá-las. Diante disso, é preciso usar a evidência externa, cuja relevância para a nossa sociedade nem sempre está completamente estabelecida.

\section{FATO RES EX TRA-ESC O LARES}

Entre os fatores extra-escolares, tanto a organização da sociedade como a da família podem ser o ponto de partida de ações direcionadas à melhoria dos resultados educacionais. Embora reconhecendo que essas duas estruturas se influenciam mutuamente e que as melhores políticas incluirão aspectos de ambas, para efeitos desta apresentação elas serão tratadas separadamente.

Nesse tema duas posições extremas devem ser evitadas. De um lado, a idéia de que a política deve prescrever tudo, padronizar a escola e o ensino. Essa idéia aparece tanto entre os que ingenuamente pensam a escola como uma "indústria de serviço", cujos processos podem ser padronizados, como entre os que advogam que a igualdade de tratamento em uma sociedade democrática exige uma escola com projeto pedagógico único. Certamente, em um país tão diverso como o Brasil, modelos únicos estão fadados ao fracasso. Não há tampouco evidência de efetividade das políticas que sugerem escolher apenas um ou dois pontos como cruciais para a transformação do sistema escolar e esperar que o resto venha como conseqüência. Essa posição é defendida com alguma freqüência em artigos publicados na grande imprensa. Na realidade, a mudança do patamar de desempenho dos alunos do ensino fundamental brasileiro é um problema complexo que exige soluções complexas e plurais.

\section{Valores Sociais}

A escola reflete a organização e os valores da sociedade na qual se insere. Seus valores estruturais e suas condições objetivas de desenvolvimento facilitam ou dificultam a implementação exitosa da educação escolar. 
A escola é uma instituição que oferece principalmente oportunidades para a aquisição de competências cognitivas. Mas não está claro se os alunos de hoje desejam isso. Um valor muito presente na sociedade atual é o da gratificação imediata, algo que a escola não pode oferecer. Entre tantas razões para que isso não aconteça causas disso destaca-se a impossibilidade, para muitos, de vencer as enormes barreiras impostas pela estratificação social por meio de ações individuais.

A idéia, tão poderosa nas gerações anteriores, de que a freqüência à escola se justifica pela melhoria que traz em termos de oportunidades de empregos e da possibilidade de apreciar as coisas belas feitas pelo ser humano nas ciências e nas artes, já não tem o mesmo impacto. Ou seja, valores importantes da sociedade atual vão na contramão da escola como instituição. Como conseqüência, muitos alunos desenvolvem pouca motivação para adquirir os conhecimentos escolares. As famílias, influenciadas pela mesma cultura, empenham-se menos que o necessário para o bom andamento do aprendizado, por exemplo, não criando uma rotina diária de estudos e leitura e de realização dos deveres de casa.

No Brasil, temos grandes dificuldades de cunho social que impedem o funcionamento eficaz das instituições escolares, principalmente aquelas situadas na periferia das grandes cidades. As duras condições econômicas da maioria ali residente e a completa exclusão social de muitos tornam a escola algo externo a vida dos alunos. Para eles, todas as energias vão para a sobrevivência. Essa situação tem levado, com alguma freqüência, a uma posição de que a função da escola é, sobretudo, a construção de uma nova sociedade. Essa idéia levada ao extremo é exageradamente imobilista já que sugere que apenas em uma sociedade ideal é possível uma escola de qualidade. Mas é exatamente em uma sociedade desigual e no estágio de desenvolvimento social como a nossa que a existência de uma boa escola é mais necessária. Mudanças sociais lentas, nas palavras de Sloat e Willms (2002), acabam mudando o patamar de aprendizado de cada sociedade, elevando-a, e com isso aumentando a qualidade do ensino, e horizontalizando-a, o que torna o sistema mais eqüitativo. Um bom exemplo é o esperado impacto positivo resultante do progressivo aumento da escolaridade das mulheres.

Como qualquer instituição, a escola funciona melhor quando há demanda na sociedade pela sua competência. No Brasil, uma grande porcentagem de 
pais de alunos da escola fundamental teve uma escolarização precária, o que talvez explique que muitos ainda estejam satisfeitos com o acesso à escola oferecido a seus filhos, mesmo que este acesso seja a uma escola de baixa qualidade. Além disso, parte importante da cidadania que poderia demandar e conseguir mais está fora da escola pública, às vezes em uma escola particular de baixa qualidade. No entanto, a PNAD de 2003 registra que a média de anos de estudo das mulheres de 20 a 24 anos é atualmente de 8,9 anos. Assim, as futuras mães serão mais educadas, e, portanto, terão mais condições de lutar por melhores escolas para seus filhos.

\section{Políticas públicas}

Uma forma potencialmente efetiva de impactar os resultados escolares de alunos é introduzir mudanças na legislação educacional. Porém, como indica o modelo conceitual adotado, a associação entre uma nova lei e a melhoria do aprendizado dos alunos é apenas indireta. Essa nova política terá de incidir sobre a escola que, por sua vez, modificará a ação do professor, e este, na sua interação com os alunos, viabilizará o aparecimento dos resultados. Mas muitas leis são promulgadas sem as necessárias evidências de que seus dispositivos têm capacidade de influenciar toda essa cadeia necessária para que surjam os efeitos pretendidos.

capítulo sobre educação da Constituição de 1988, o Fundo de Manutenção e Desenvolvimento do Ensino Fundamental e de Valorização do Magistério - Fundef - e a Lei de Diretrizes e Bases da Educação Nacional LDB - são exemplos de sucesso. A nova Carta consagrou o direito ao ensino fundamental como direito subjetivo, decisão que refletiu na oferta desse nível de ensino. Além disso, introduziu os princípios da descentralização, da cooperação entre os entes federados e da democratização da gestão, fundamentais para a construção de sistemas educacionais adequados para um país tão diverso quanto o Brasil.

A LDB, como mostra Mello (2004), incluiu, além dos princípios presentes na Constituição, inovações como a ênfase na autonomia da escola, a centralidade da proposta pedagógica e a importância da informação e da avaliação para a gestão das escolas e dos sistemas, conceitos que facilitam a organização mais efetiva das escolas. $\bigcirc$ Fundef, ao implementar a idéia da distribuição de recursos 
baseando-se em percentuais iguais pelos alunos de um mesmo estado, teve reflexos no salário dos professores dos estados mais pobres da federação.

Há, porém, um acúmulo de leis e acordos feitos sem a devida consideração do impacto no ensino que dificultam enormemente o funcionamento regular do sistema. Por exemplo, em alguns sistemas os professores podem faltar sem justificativa prévia algumas vezes ao mês. Nessas circunstâncias, um trabalho importante do diretor de uma escola grande é, a cada dia, improvisar a substituição, pois ele só sabe com quais professores pode contar minutos antes do início das aulas. Em outros sistemas, o diretor pode ser transferido durante o ano letivo, e em quase todos o número de professores fora da sala de aula é muito grande. Um dado do Censo Escolar pouco citado é que na rede pública há um contrato de professor - uma função docente - para cada 22 alunos, mas são poucas as salas de aula que não ultrapassam esse número de alunos. Criam-se direitos desconsiderando a função precípua da escola de atendimento às necessidades de aprendizado de seus alunos.

\section{Recursos}

Muitos analistas indicam a necessidade do aumento dos recursos destinados ao sistema educacional para a obtenção de melhores resultados. Segundo dados do projeto World Education Indicators 6 , o Brasil investe em educação 5, I \% de seu Produto Interno Bruto. Este percentual é um pouco menor que a média $(5,43 \%)$ e coloca o Brasil entre os 15 países com menor gasto percentual em educação no ranking dos 44 países para os quais existem dados e que congregam grande parte da população mundial. Há, portanto, algum espaço para aumento do investimento em educação, mas não são muitas as opções, considerando-se os atuais patamares da carga tributária brasileira. Pinto (2002) sugere que durante os anos que são necessários para a superação da situação de qualidade precária em que se encontra o ensino básico, o Brasil deveria investir até 10\% de seu PIB na educação, aumento que, segundo o autor, deveria vir de remanejamentos de outras áreas. Esta duplicação do percentual é muito pouco provável, considerando as carências do país em outras áreas.

6. Os dados estão disponíveis no sítio: http://www.uis. unesco.org/TEMPLATE/html/Exceltables/ WEl2002/table I 2.xls. 
É mais razoável imaginar um aumento seletivo de recursos e mudanças na forma de alocação. Nesse sentido, loschpe (2004) tem uma proposta radical. Defende a alocação ao ensino básico dos recursos atualmente usados para subsidiar a educação básica e superior dos filhos das famílias de posição econômica mais favorecida através do abatimento no Imposto de Renda e da gratuidade das universidades públicas. Nesta hipótese, aumentariam os recursos públicos para a educação básica.

Aumentos seletivos de recursos, principalmente para melhorar os salários dos professores dos sistemas públicos efetivamente envolvidos com o ensino, são claramente necessários. Mas estes novos recursos devem ser alocados com a contrapartida de melhoria dos resultados em prazos acordados.

Esse é o exemplo paradigmático de tema que precisa ser desinterditado. Hoje a produção acadêmica nessa área está muito dividida. Há os que aceitam a relevância para a nossa realidade da evidência internacional de que o aumento de recursos não produz resultados. Não se considera que esta evidência foi produzida em sociedades nas quais o sistema escolar já conseguiu se apareIhar em termos de infra-estrutura e de pessoal, situação de que estamos longe. $\bigcirc$ outro lado, sem nenhuma evidência empírica, aceita que apenas a alocação de mais recursos produzirá os resultados necessários, mesmo que sejam usados para aumentar salários de quem não está atuando na escola, e sem a existência de um sistema de monitoramento de resultados. Um novo tipo de trabalho acadêmico que rompa essas barreiras e seja apoiado em evidências empíricas precisa surgir. No entanto, há muitas dificuldades institucionais e políticas para a implementação deste tipo de proposta.

\section{Gestão dos sistemas}

Muitos autores, como Mello (2004), mostram de modo convincente o enorme potencial da política de autonomia da escola, já consagrada na atual LDB, como estratégia essencial para o seu melhor funcionamento e a conseqüente melhoria dos resultados de seus alunos. Assim, o papel da administração dos sistemas de ensino é o de apoiar as escolas no desenvolvimento e implementação de seu projeto pedagógico e avaliar pelos resultados obtidos se os direitos dos alunos por uma educação de qualidade estão sendo respeitados nas opções autônomas tomadas pela escola. 
Essas duas funções, de apoio e avaliação, não são as que predominam nas secretarias municipais e estaduais de Educação, completamente devotadas a controles burocráticos das escolas e à supervisão de programas comuns a todo o sistema. Diante disso, esses órgãos têm pouco impacto na qualidade da educação escolar, que é, paradoxalmente, sua mais importante função.

Uma fonte de estudo ainda pouco utilizada para a busca da organização mais efetiva dos sistemas de ensino é a análise comparativa com os sistemas privados de ensino. Naturalmente, a comparação bruta da média dos alunos destes dois tipos de escolas é muito pouco informativa. Nos níveis intermediários de posição econômica há alunos suficientes em ambos os sistemas que permitem uma comparação mais sólida. Por exemplo, Soares e César (2002) distribuíram os alunos do Saeb 200 I que fizeram o teste de Matemática em grupos homogêneos quanto ao nível socioeconômico e mostraram que, dentro dos grupos intermediários, o melhor desempenho dos alunos que freqüentam o sistema privado de ensino é superior ao melhor desempenho dos que freqüentam o ensino público.

Nos últimos anos, surgiram no Brasil várias redes privadas de ensino que constituem hoje verdadeiros sistemas educacionais privados. O núcleo central apóia a produção do projeto pedagógico da escola e fornece os materiais didáticos. Se isto produz uma grande padronização no ensino das escolas conveniadas, em contrapartida há oferta de capacitação do professor. Recentemente, esses sistemas passaram a oferecer também os serviços de avaliação educacional.

Não está claro, com a informação disponível no momento, como estas experiências podem ajudar a organização dos sistemas públicos, mas os resultados obtidos chamam a atenção, mesmo levando em conta o fator socioeconômico e a grande diferença no número de funcionários dessas redes e das secretarias de Educação em relação ao número de alunos que atendem.

\section{Responsabilização}

Uma forma de relação entre a escola e o sistema cada vez mais considerada (Fernandes, 2006) é a chamada responsabilização social, tradução do termo da língua inglesa accountability. São vários os formatos possíveis, mas em todos eles está implícita a idéia de alocação seletiva de mais recursos tendo 
como contrapartida os resultados obtidos. Brooke (2006) faz uma descrição do atual estágio dessa discussão no Brasil.

p primeiro componente de um sistema de responsabilização escolar é a coleta da evidência de que a escola mantém o aluno matriculado. Isso porque a melhor maneira de obter melhores resultados na escola é excluir os alunos com alguma dificuldade de aprendizagem, opção usada durante anos na escola pública brasileira. Em segundo lugar, a escola deve ser vista pelo que acrescenta aos alunos, e não pelo nível que eles atingem em um dado momento histórico. Portanto, o sistema de cobrança de resultados cognitivos deve ser organizado de forma longitudinal, incorporando-se a idéia do valor agregado como linha mestra da análise dos dados de desempenho. Se o sistema de responsabilização for construído com base nessas duas dimensões, inclusão e valor agregado, e for implantado junto com a autonomia da escola, é razoável esperar melhorias.

No entanto, antes de se pensar na implementação desse tipo de organização do sistema, é preciso estudar outras experiências, principalmente na Inglaterra, onde começaram, e nos Estados Unidos, onde se transformaram em controversas políticas públicas. Há um pequeno número de experiências brasileiras que também merecem atenção.

\section{Seleção}

A melhor estratégia disponível para que um estabelecimento escolar melhore seus resultados cognitivos é selecionar os alunos. Há dois tipos de seleção: a socioeconômica e a cognitiva. As escolas técnicas federais são um exemplo eloqüente da eficácia de se produzir bons resultados através da seleção cognitiva. Seus exames de admissão são muito concorridos, de modo que os alunos aceitos são sempre estudantes com ótimo perfil acadêmico. A presença de um grupo expressivo de alunos academicamente preparados e motivados cria na escola um ambiente onde tudo concorre para o aprendizado cognitivo.

As escolas particulares dos grandes centros urbanos recorrem á seleção socioeconômica. No Brasil, existe grande associação entre o cultural e o econômico, o que faz com que essa seleção acabe produzindo também ambientes adequados para o aprendizado cognitivo. No entanto, nessas escolas há, 
concomitantemente, um outro mecanismo importante, que é a exclusão anual dos alunos que por motivos variados não se adequaram ao projeto da escola. A combinação dessas políticas de seleção e exclusão é a melhor explicação para os resultados obtidos por esses estabelecimentos.

É claro que nesses exemplos há alunos de excelente perfil cognitivo em escolas com boas condições. É possível, através de modelos estatísticos, anular o efeito do nível socioeconômico dos alunos. Mas esses exercícios continuam a mostrar inequivocamente o efeito da seleção, pois, apesar da correção pelo nível socioeconômico dos alunos e do padrão das escolas, aquelas com maior grau de seleção de alunos apresentam os melhores resultados.

Ainda não existem estudos usando a escala do Saeb que avaliem experiências como as de ONGs que oferecem boas escolas para grupos de alunos não selecionados previamente.

Diante de tudo isto, a contribuição da estratégia da seleção de alunos será necessariamente pequena para um projeto educacional público. No entanto, é preciso considerar que, dadas as formas de alocação de alunos em diferentes escolas, os bons alunos das escolas públicas, que seriam fortes candidatos a ingressar nas universidades públicas e a passar nos concursos públicos para os bons empregos, têm sua vida acadêmica enormemente dificultada. Neste sentido, as experiências como a da Embraer, que mantém em São José dos Campos uma escola para egressos da escola pública local, e os vários projetos de ação social, como a ONG Bom Aluno e o projeto Ismart da Fundação Lemann, entre tantos outros, precisam ser estudados como fonte de possíveis idéias para o setor público. Talvez neste momento histórico, a seleção de alunos possa ter algum papel dentro de um projeto maior de melhoria do ensino básico brasileiro visando mais qualidade e eqüidade.

\section{Família e comunidade}

O modelo de Nechyba, McEwan e Older-Aguilar (2004) descreve possíveis mecanismos pelos quais a família e a comunidade na qual se insere estão associadas aos resultados escolares dos estudantes. Segundo esse modelo, o impacto da família e da comunidade se manifesta através de um grande número de canais, desde o padrão genético dos pais, passando pela sua educação e ocupação, até os efeitos do ambiente social freqüentado. 
A partir de suas características intrínsecas, as famílias fazem várias escoIhas. Primeiramente, tomam decisões intermas que incluem, entre outras coisas, o estilo de criação dos filhos, a criação de rotina diária na casa e o investimento financeiro nos filhos. Depois, as famílias escolhem uma comunidade para viver, que influenciará os resultados das crianças através de vários mecanismos denominados efeito de vizinhança. Finalmente, os pais optam por se envolver ou não nas atividades da escola e nas tarefas de aprendizagem que ocorrem no âmbito da residência. $\bigcirc$ modelo conceitual considera ainda que os alunos, influenciados ou não por seus pais, escolhem um grupo de referência dentro da escola que terá grande impacto na sua vida escolar. Assim, o desempenho cognitivo seria influenciado por uma infinidade de fatores relacionados com as famílias, as comunidades e as escolas. $\bigcirc$ desafio dos pesquisadores é isolar esses efeitos de forma convincente, o que ainda não foi feito, principalmente na realidade brasileira.

Esse modelo conceitual foi desenvolvido como estratégia de síntese da literatura existente para uso do ministério da Educação da Nova Zelândia. Sua relevância para a realidade brasileira não é total, em particular por assumir escolhas que, no caso brasileiro, não ocorrem autonomamente. No entanto, ao sugerir uma explicação plausível para a cadeia de eventos que a partir da ação da família levam ao desempenho escolar, ajuda na formulação de políticas escolares e não escolares.

\section{PO LÍTICAS ESC O LARES}

Como já dissemos ao tratar do efeito da escola, o papel do estabelecimento escolar é mudar a trajetória de desempenho traçada pela sociedade para um dado aluno. Antes de examinar o que a pesquisa nessa área indica que é possível fazer e por que caminhos, é necessário demonstrar empiricamente que essa abordagem é viável.

\section{Evidências empíricas}

Em 2003, todas as escolas públicas de Belo Horizonte participaram do Simave, projeto de avaliação do desempenho cognitivo dos alunos das escolas de Minas Gerais que utiliza a mesma escala do Saeb para expressar seus resul- 
tados. Neste item, apresentamos alguns resultados referentes à oitava série do ensino fundamental ${ }^{7}$ como evidência de que existem grandes possibilidades de melhorar os resultados escolares mediante políticas escolares.

Para uma análise mais convincente desses dados, é preciso comparar os resultados de alunos de escolas com níveis socioeconômicos similares. Para isto, usando-se as informações fornecidas pelos alunos ao responder o questionário contextual distribuído junto com o teste do Simave, construiu-se um índice socioeconômico. Esse questionário inclui itens que captam de forma indireta a renda do aluno e de forma direta a escolaridade dos pais. Os detalhes da construção da medida estão em Soares e Andrade (2006). Tomou-se como nível socioeconômico da escola a média do nível socioeconômico dos alunos, e as escolas foram distribuídas em cinco níveis de acordo com esse indicador. Com esse cuidado é possível comparar de forma adequada o desempenho das escolas. Os resultados estão na tabela 2.

Verifica-se que escolas que atendem a um alunado semelhante têm resultados que diferem em até 60 pontos, diferença equivalente a mais de dois anos de escolarização. Dado que essa comparação é feita dentro de escolas da mesma cidade com alunos do mesmo nível socioeconômico fica claramente constatado que há espaço para melhorias substanciais através de ação nas escolas.

Isso significa que, apesar das pesadas restrições impostas à escola pelos valores vigentes na sociedade, pelas leis educacionais do país e pela organiza-

TABELA 2

RESULTADO DE ESCOLAS DA REDE PÚBLICA DE BELO HORIZONTE EM MATEMÁTICA NA 8 SÉRIE, POR QUINTIS DO NÍVEL SOCIOECONÔMICO

\begin{tabular}{ccccc}
\hline Quintil do NSE* da Escola & Número de Escolas & Mínimo & Máximo & Diferença \\
\hline I & 46 & 196 & 253 & 57 \\
2 & 46 & 182 & 262 & 80 \\
3 & 46 & 213 & 265 & 78 \\
4 & 46 & 208 & 276 & 84 \\
5 & 46 & 233 & 302 & 69 \\
\hline
\end{tabular}

Fonte: Simave, 2003

* NSE - nível socioeconômico.

7. As escolas da prefeitura de Belo Horizonte usam um sistema de ciclos e assim os alunos testados no Simave pertencem ao $2^{\circ}$ ano do segundo ciclo. 
ção dos sistemas públicos de ensino e características da comunidade a que a escola serve, há espaço no estabelecimento escolar para a implantação de políticas e práticas que propiciem melhor aprendizado dos alunos. Como síntese da melhoria possível, considerando a diferença entre as escolas com pior e melhor desempenho, pode-se estabelecer a meta de 40 pontos como aumento viável apenas com políticas escolares para as atuais escolas. A conquista dessa meta criaria as condições para se conhecer melhor o que devemos fazer para enfrentar os grandes desafios, como os que nos indica o Programa Internacional de Avaliação Comparada - Pisa.

\section{Gestão da escola}

modelo conceitual apresentado na figura I mostra que dentro da escola há dois importantes processos que interagem para a produção do desempenho dos alunos: a gestão escolar e o ensino.

A gestão, responsabilidade da direção da escola, tem como função administrar o projeto pedagógico da escola, as pessoas que constituem a comunidade escolar e os aspectos físicos e financeiros da organização escolar. Esse modelo admite implicitamente que a escola já tenha uma rotina, o que nem sempre ocorre em nossa a realidade, onde são comuns as interrupções de funcionamento pelos motivos mais variados. Assim, o primeiro objetivo da gestão escolar na escola pública brasileira é implantar uma rotina de funcionamento da escola, de forma que os recursos nela existentes possam ser usados para atender às necessidades de aprendizagem dos alunos. Ou seja, conhecer os alunos e garantir sua presença diária assim como a dos professores constituem a primeira missão do gestor escolar. Outras providências simples são: dispor os melhores professores para atender os alunos mais vulneráveis e não trocar de professor e de turma durante o ano letivo, garantir que os alunos tenham orientação segura via bons materiais didáticos e envolver as famílias na educação de seus filhos. Uma hipótese para a diferença observada entre os resultados das escolas particulares e das escolas públicas no Brasil é que as primeiras implementam essas rotinas com mais freqüência. Assim, a diferença que favorece a escola particular se deveria não ao seu bom funcionamento, mas ao mau funcionamento da escola pública.

Uma das medidas de maior impacto no aprendizado dos alunos captada na escola é a distribuição das turmas. Quando se colocam na mesma turma os 
alunos com melhor capital cultural e mais motivação escolar, cria-se um ambiente favorável ao aprendizado, que logo se traduz em melhores resultados cognitivos. No entanto, segregar os melhores alunos é uma política tão perversa quanto criar turmas apenas com alunos de baixo desempenho. Essa medida é uma ferramenta que deve ser usada sempre a favor do aluno e, portanto, respeitar o dinamismo de seu aprendizado.

A pesquisa sobre a estrutura de uma escola eficaz é usualmente sintetizada em listas de fatores presentes nelas. As sínteses de Cotton (2004) e Sammons et al. ( 1995) feitas para o governo britânico são constituídas de onze fatores que deveriam ser encontrados na boa escola:

I. Direção (socialmente legítima, profissionalmente competente, firme e objetiva e participativa).

2. Visão e metas compartilhadas (unidade de propósitos, decisões colegiadas, todos são responsáveis).

3. Ambiente de aprendizagem (clima de ordem, ambiente de trabalho agradável).

4. Concentração no ensino/aprendizagem (bom uso do tempo, orientação para obtenção de resultados cognitivos).

5. Ensino estruturado (organização eficiente, clareza de objetivos, ensino com um sólido projeto pedagógico subjacente).

6. Altas expectativas (altas expectativas sobre todos, expectativas comunicadas, proposição de desafios intelectuais).

7. Reforço positivo (disciplina clara e acordada, feedback).

8. Monitoramento (monitoramento do desempenho dos alunos, avaliação da escola).

9. Direitos e responsabilidades dos alunos (auto-estima, responsabilidade, controle do trabalho).

10. Parceria família/escola (envolvimento dos pais no aprendizado dos filhos).

I I. Organização voltada para a aprendizagem (desenvolvimento da profissionalização e do clima organizacional).

Embora esses princípios pareçam relevantes para qualquer escola, seu potencial, assim como de outros similares, para a melhoria da escola pública 
brasileira precisa ser empiricamente verificado. A pesquisa sobre a escola eficaz é uma área ainda incipiente no Brasil, onde o paradigma dominante de pesquisa educacional não privilegia este tema, mas podemos destacar, entre outros, os trabalhos qualitativos feitos no âmbito do Saeb 1999, o trabalho de Alves (2006), na realidade um estudo longitudinal de pequeno porte mas que pelo fato de ter incorporado estudos de caso traz uma contribuição singular, e os do Resende (2005), que estudou escolas de sucesso no vestibular, Soares (2005), que faz uma síntese da área citando as outras evidências nacionais, e Game (2002), que relata um estudo de três escolas do sistema estadual de ensino de Belo Horizonte.

\section{O professor}

modelo conceitual registra de forma proeminente a importância do professor para o aprendizado do aluno, já comprovada tanto na literatura internacional como nacional. Assim, qualquer intervenção escolar que tenha como objetivo melhorar o desempenho dos alunos passa necessariamente por mudanças concretas no grau de satisfação e comprometimento com a escola e na capacidade técnica de implementação do projeto pedagógico pelo professor. A síntese da literatura internacional feita por Darling-Hammond (1999) continua atual.

Isto exige, no caso de alguns sistemas públicos, aumentos substanciais de salários, que deveriam ter como contrapartida um envolvimento maior no projeto pedagógico da escola. Sua implementação exige, porém, uma engenharia institucional que ainda está por ser inventada, pois são muitas as dificuldades legais e políticas que impedem esse tipo de ação. Há evidências de que apenas a alocação de mais recursos não é garantia de resultados, por exemplo, quando se observam diferenças nos salários dos professores das redes municipais e estaduais em grandes cidades, mas pouca diferença nos resultados dos alunos.

Para produzir um impacto de longo prazo são necessárias mudanças na formação inicial do professor. Há um diagnóstico amplamente aceito de que a atual formação do professor não é adequada à escola, mas não se consegue chegar a um acordo sobre como proceder às mudanças necessárias. A formação continuada precisa ser feita de maneira articulada com o projeto pedagó- 
gico da escola. Como este quase nunca existe de fato, gasta-se muito em programas generalistas que produzem poucos resultados.

\section{CON CLUSÃO}

O Saeb, além da informação sobre o nível dos alunos em relação a competências matemática e leitora, fornece importantes subsídios para a compreensão dos fatores associados ao processo de ensino e aprendizagem. Embora nem todos os fatores considerados no modelo conceitual usado neste texto sejam medidos no Saeb, seus resultados confirmam as relações já registradas na literatura internacional. Isso é apresentado em detalhe no relatório sobre os fatores associados ao desempenho preparado para o Saeb 2003 e disponível no sítio do Inep.

A ação ideal para a melhoria dos resultados dos alunos da educação fundamental deveria partir de propostas que harmonizem valores da sociedade, as leis que regem os sistemas de ensino, uma administração eficiente e políticas escolares fundamentadas em evidências, tudo isso apoiado por uma ação decidida das famílias. Mas não seria essa harmonia apenas um sonho em uma sociedade democrática, onde o conflito de idéias estará necessariamente sempre presente?

As intervenções escolares devem ser planejadas respeitando-se as teorias já testadas através da coleta de evidências empíricas, mesmo reconhecendo-se que as teorias educacionais explicam os resultados apenas na sua tendência geral, e assim expressam-se junto com uma grande variação individual. Neste sentido, é preciso reafirmar que muito do que se registrou neste texto ainda não pôde ser verificado empiricamente no Brasil, que só lentamente vai investindo recursos para a pesquisa empírica da realidade educacional.

Está muito claro que há, hoje, um amplo espaço para a ação nas estruturas escolares com vista à melhoria do desempenho dos alunos da educação fundamental brasileira. Para a apresentação das idéias centrais deste texto foi necessário isolar as várias estruturas que impactam os resultados escolares. $\mathrm{Na}$ prática, há uma grande sinergia entre elas. Por exemplo, as leis educacionais refletem a sociedade, mas também podem induzir mudanças na sociedade no médio e longo prazo. A família e a comunidade podem ser não apenas fonte 
de restrições para a ação da escola, mas também parceiras na implementação do projeto pedagógico da escola.

Qualquer ação para melhoria dos resultados escolares precisa ter um escopo claro e metas muitas bem definidas, cujos resultados devem ser aferidos em uma métrica nacional, hoje representada por aquela utilizada no Saeb. Considerando as grandes desigualdades sociais, características de nossa sociedade, o objetivo não pode ser apenas a melhoria do nível de desempenho dos alunos, mas também a eqüidade, outro ponto que deve ser enfatizado no projeto pedagógico das escolas.

Ao contrário do que dizem muitos comentaristas da questão educacional brasileira, ainda não há consenso sobre como melhorar os resultados cognitivos da educação básica brasileira. As análises são ainda dominadas por uma unicausalidade, difícil de aceitar, e as propostas se baseiam no fato de que todas as dificuldades de aprendizagem devem ser creditadas à exclusão social dos alunos ou à incapacidade da escola de lidar com o alunado que deve atender. A solução sugerida também é única: basta um substancial aporte de recursos financeiros. Embora esses elementos devam estar presentes tanto em uma análise criteriosa da realidade como em uma proposta de ação, a melhoria do ensino é um problema muito complexo que pede soluções múltiplas. Por isso, e considerando-se as experiências, seja da escola particular brasileira, seja das escolas internacionais, deve-se considerar o aumento da autonomia das escolas, com aumento substancial dos recursos financeiros e humanos que hoje administram, como uma possível estratégia de ação. A existência de grandes diferenças de desempenho entre escolas que atendem a alunos muito semeIhantes reforça a idéia de que, sem prejuízo de ações extra-escolares, há muito que fazer dentro das escolas.

Como afirmam Newmann et al. (200 I), as intervenções escolares com chance de impacto no desempenho dos alunos devem estar organicamente associadas ao seu projeto pedagógico, isto é, ao referencial curricular, às formas de instrução e avaliação e à ênfase na aprendizagem dos alunos.

\section{REFERÊN CIAS BIBLIO GRÁFICAS}

ALVES, M. T. G. Efeito-escola e fatores associados ao progresso acadêmico dos alunos entre o início da $5^{a}$ série e o fim da $6^{a}$ série do ensino fundamental: um estudo longitudinal em 
escolas públicas no município de Belo Horizonte. Belo Horizonte, 2006. Tese (dout.) Programa de Pós-Graduação em Educação, Faculdade de Educação, Universidade Federal de Minas Gerais.

BARROS, R. P. et al. Determinantes do desempenho educacional no Brasil. Pesquisa e Planejamento Econômico, v.31, n. I, p. I-42, 2001 .

BROOKE, N. As Perspectivas para os sistemas de responsabilização educacional no Brasil. Belo Horizonte, 2006. mimeo.

CASTRO, C. M. Educação técnica: a crônica de um casamento turbulento. In: BROCK, N.; SCHWARTZMAN, S. (orgs.) Os Desafios da educação no Brasil. Rio de Janeiro: Nova Fronteira, 2005. p.34-43.

COHEN, D. K.; RAUDENBUSH, D.; BALL, D. L. Resources, instruction and research. In: MOSTELLER, F; BORUCH, R. (org.) Evidence matters: randomized trials in education research. Washington: Brookings Institution Press, 2002. p.80-1 19.

COLEMAN, J. S. et al. Equality of educational opportunity. Washington: Dept. of Health, Education, and Welfare, Office of Education, 1966.

COTTON, K. Effective schooling practices. a research synthesis 1995 update. The Northwest Regional Educational Laboratory. Disponível em: http://www.nwrel.org/scpd/esp/esp95.html. Acesso em: abr.2004.

DARLING-HAMMOND, L. Teacher quality and student achievement. a review of state policy evidence. Seattle-WA: Center for the Study of Teaching and Policy; University of Washington, 1999.

FERNANDES, R. Qualidade na educação básica. In: REUNIÃO DA ABAVE, I. Belo Horizonte, 2006.

FRANCO, C. Qualidade da educação brasileira: há como ir além do discurso sobre a importância do tema? In: REUNIÃO DA ABAVE, I. Belo Horizonte, 2006.

GAUTHIER, C. Pour une théorie de la pédagogie: recherches contemporaines sur le savoir des enseignants. Sainte-Foy, Québec: Presses de l'Université Laval, 1997.

GRUPO DE AVALIAÇÃO E MEDIDAS EDUCACIONAIS - GAME. Escola eficaz: um estudo de caso em três escolas da rede pública do Estado de Minas Gerais. Belo Horizonte: Game/ FAE/NFMG; Segrac, 2002.

IOSCHPE, G. A Ignorância custa um mundo: o valor da educação no desenvolvimento do Brasil. São Paulo: WI I Editores, 2004. 
KLEIN, R. Produção e utilização de indicadores educacionais: metodologia de cálculo de indicadores de fluxo escolar da educação básica. Revista Brasileira de Estudos Pedagógicos, v.84, n.206/208, p. 107-157, jan./dez. 2003.

KLEIN, R.; FONTANIVE, N. Avaliação em larga escala: uma proposta inovadora. Em Aberto, v. I5, n.66, p.29-34, 1995.

LEE, V. E.; BRYK, A. S.; SMITH, J. The Organization of effective secondary schools. In: DARLING-HAMMOND, L. (org.) Review of research in education. Washington: American Educational Research Association, 1993. p. I7|-268.

MEIRIEU, P. L'École entre la pression consumériste et l'irresponsabilité sociale. In: LESSARD, C.; MEIRIEU, P. L'Obligation de resultants en education: evolution, perspectives et enjeux inernationaux. Laval: Les presses de L'Université de Laval, 2005.

MELLO, G. N. Educação escolar brasileira: o que trouxemos do século $X X$ ? Porto Alegre: Artmed, 2004.

NECHYBA, T.; MCEWAN, P.; OLDER-AGUILAR, D. The Impact of family and community resources on student outcomes: an assessment of the international literature with implications for New Zealand. 2004.

NEWMANN, F. M. et al. Instructional program coherence: what is and why it should guide school improvement policy. Educational Evaluation and Policy Analysis, v.23, n.4, p.297-32 I , 200 I .

PINTO, J. M. R. Financiamento da educação no Brasil: um balanço do Governo FHC (19952002). Educação \& Sociedade, v.23, n.80, p. 108-135, 2002.

RESENDE, M. A. M. Por que escolas com características semelhantes apresentam resultados tão diferentes? Belo Horizonte, 2005. Dissert. (mestr.) Programa de Pós-Graduação em Educação, Faculdade de Educação, Universidade Federal de Minas Gerais.

RIOS-NETO, E. L. G. O Método probabilidade de progressão por série. In: RIOS-NETO, E. L. G.; RIANI, J. L. R. (orgs.) Introdução à demografia da educação. Campinas: Associação Brasileira de Estudos Populacionais - Abep, 2004. p. 143 - 145.

SAMMONS, P.; HILLMAN, J.; MORTIMORE, P. Key characteristics of effective schools. London: Office for Standards in Education, 1995.

SANTOS, L. L. C. P. Políticas públicas para o ensino fundamental: parâmetros curriculares nacionais e sistema nacional de avaliação (Sseb). Educação \& Sociedade, Campinas, v.23, n.80, p.349-370, 2002.

SCHEERENS, J.; BOSKER, R. J. The Foundations of educational effectiveness. Oxford: Elsevier Science, 1997. 
SLOAT, E.; WILLMS, J. D. A Gradient approach to the study of childhood Vulnerability in vulnerable children. Alberta: The University of Alberta Press, 2002.

SOARES, J. F. O efeito da escola no desempenho cognitivo de seus alunos. In: SOUZA, A. de M. e. Dimensões da avaliação educacional. Petrópolis: Vozes, 2005. p. 174-204.

Quality and equity in brazilian basic education: facts and possibilities. In: BROCK, C.; SCHWARTZMAN, S. (orgs.) The Challenges of education in Brazil. Oxford: Oxford University Press, Symposium Books, 2004. p.69-88.

SOARES, J. F; ANDRADE, R. J. Indicadores de qualidade nas escolas municipais de Belo Horizonte In: REUNIÃO DA ABAVE, I. Anais. Belo Horizonte, 2006.

Nível socioeconômico, qualidade e eqüidade das escolas de Belo Horizonte. Ensaios em Avaliação Educacional. (no prelo)

SOARES, J. F; CÉSAR, C. C. Comparação do desempenho em matemática dos alunos das escolas públicas e privadas: a evidência do Saeb 99. Rio de Janeiro, 2002. mimeo.

UNESCO. Education for all (EFA) global monitoring report 2005: the quality imperative, 2005. Disponível em: http://portal.unesco.org/en/ev.php-url_id=29008\&url_do= do_topic\&url_section=20 I.html. Acesso em: dez. 2005.

Recebido em: março 2006

Aprovado para publicação em: junho 2006 